\title{
College Students' Perceptions of Relations with Parents and Academic Performance
}

\author{
Kerry A. Schwanz ${ }^{1, *}$, Linda J. Palm ${ }^{1}$, Crystal R. Hill-Chapman ${ }^{2}$, Samuel F. Broughton ${ }^{2}$ \\ ${ }^{1}$ Department of Psychology, Coastal Carolina University, Conway, South Carolina, USA \\ ${ }^{2}$ Department of Psychology, Francis Marion University, Florence, South Carolina, USA \\ *Corresponding author: kaschwan@coastal.edu
}

Received December 23, 2013; Revised January 03, 2014; Accepted January 06, 2014

\begin{abstract}
The relationship between parent relations and college students' academic performance was examined in two studies using samples of students enrolled in two southeastern liberal arts universities $(N=466)$. T scores on the Relations with Parents subscale on the college version of the Behavior Assessment System for Children-2 served as the measure of student perception of parent relations and academic performance was measured using official university GPA and probation/suspension data. Results for the first study indicated a significant positive correlation between parent relations scores and GPAs. Additionally a significant negative correlation was found between parent relations scores and probation/suspension status. When gender differences were examined, parent relations scores accounted for more variance in academic performance for women than men. Systematic replication of the study at a nearby liberal arts university produced findings congruent with the initial investigation. Implications for college personnel who work with academically at- risk students are discussed.
\end{abstract}

\section{Keywords: parent relations, academic performance, college probation/suspension, college students}

Cite This Article: Kerry A. Schwanz, Linda J. Palm, Crystal R. Hill-Chapman, and Samuel F. Broughton, "College Students' Perceptions of Relations with Parents and Academic Performance." American Journal of Educational Research 2, no. 1 (2014): 13-17. doi: 10.12691/education-2-1-3.

\section{Introduction}

A considerable body of research documents the importance of parental involvement and support to psychosocial and academic adjustment during childhood and early-adolescent developmental periods [4,5,7,10,15]. The need for parental support may not end when students enter college and young adulthood. The transition from high school and living with parents at home to college and living independently can be stressful for many young adults. Along with adjusting to the college social environment, most students experience increased academic demands. Maintaining a healthy relationship with parents during the college years may be very beneficial to young adults.

Professionals in higher education believe that compared to previous generations there has been a substantial increase in parental involvement in young adults' lives during the college years for the Millennial Generation, the cohort of students born after 1982 [3,14]. These highly involved parents have often been referred to as "helicopter parents" [11,13] suggesting that they "hover" over their adult children waiting to swoop down and assist them at any moment. While parental over-involvement that is developmentally inappropriate has been associated with some problematic traits in young adults such as depression, feelings of entitlement, decreased emotional regulation, and lower life-satisfaction, supportive parental involvement that fosters autonomy may be beneficial
$[9,12,18,19]$. Furthermore, there is evidence that Millennnial Generation students desire this level and type of parental support [2]. Kolkhorst, Yazedjian, and Toews [11] examined college student perceptions of parental involvement and found that students reported seeking various forms of parental support and that these interactions were positive in nature. Most students felt that their parents supported them but also facilitated their independence by trusting them to make their own decisions. The minority of students who reported dissatisfaction with parental support actually expressed a desire for more involvement on the part of their parents. Pizzolato and Hicklen [14] specifically examined parental involvement in college students' decision making. They found that when students were asked to report an important decision that they made in their lives, more than half of the students did not solicit parental help in their decision making. When students did consult with parents, the majority did so to gain a different perspective on the issue rather than asking their parents to make the decision for them. This finding suggests that there is a change in the dynamic of the parent-child interaction for college-age students, where parental input is considered but the young adult is no longer completely dependent on parents to make decisions [14]. Sorokou and Weissbrod [20] examined gender differences in first-year male and female college students' attachment and interaction patterns with parents. In particular, the researchers explored gender differences based on students' need and nonneed-based communications with parents. Need-based contact was 
defined as "proximity and support seeking in times of need" and nonneed-based communication as "the desire to touch base to maintain emotional connectedness" [[20]; p. 222]. The researchers found that women, more than men, were recipients as well as the initiators of non-need based interactions with parents. They also found that compared to men, women had more need-based interactions with parents that were initiated by parents. However, no significant gender differences were found for the student initiated need-based contacts. Additionally, for both men and women, the frequency of both types of contacts was positively related to the self-reported quality of attachment with parents.

While the importance of parent-student relationships in regard to students' overall well-being and college adjustment has been documented in several studies, less attention has focused on parent relations and academic achievement for the college population. Fass and Tubman [8] investigated the relationship between parent and peer attachment and academic achievement in college students. Positive correlations were found between parental and peer attachment and variables related to psychosocial adjustment such as self-esteem and optimism. However, no significant relationship was found between students' academic achievement measured by self-reported GPA and parent or peer attachment. Yelle, Kenyon, and Koerner [22] studied college students' perceptions about closeness and separateness from their parents, their adjustment to college, and their self-reported anticipated grades. These researchers found that college students who reported higher levels of connectedness to their parents also reported higher levels of positive affect. However, again in this study, no significant relationship was found between the parent variables and students' expected academic achievement. Wintre and Yaffe [21] examined college students' perceptions of parenting styles and current relationships with parents (mutual reciprocity, parental social support, and discussions about school issues with parents). Based on previous research with elementary and high school students in which an authoritative parenting style was associated with better academic performance, Wintre and Yaffe [21] conceptualized a model of parent facilitation of academic achievement in college students. These authors hypothesized that an authoritative parenting style would be indirectly related to academic achievement through its facilitation of students' positive current relationships with parents and the psychological well-being of the student. Overall results of the study established that parents have a significant, albeit small, influence on their child's adaptation to university life in general. An authoritative parental style was found to have an indirect positive relationship with students' adaptation to college, while current relationship with parents was found to have a direct positive relationship with adjustment to college. Interestingly, no parental relationship variables emerged as positive contributors to students' academic performance. For college-age men, there was no direct link between parenting styles or measures of current relationships with parents and academic achievement. However, for women, there was a direct negative relationship between a maternal authoritarian style of parenting and academic achievement. Duchesne, Ratelle, Larose, and Guay [6] conducted a longitudinal study of academic and emotional adjustment of college students. The researchers measured students' self-report about parental involvement, parental support, and adjustment to emotional and academic demands during a 2-year period from the end of high school to the end of their $2^{\text {nd }}$ year in college. Their findings indicated that students who reported high levels of parental involvement and support at the end of their first year of college self-reported higher levels of academic adjustment than students whose parents were not highly involved or supportive.

Conflicting findings have been reported in the literature regarding the relationship between parental variables and academic achievement of college students. Different methods of defining and measuring parent relations may contribute to these conflicting findings. Moreover, several researchers have used students' self-reported GPA data or anticipated grades rather than objective measures of academic achievement. The current study used a nationally normed and standardized instrument to assess parent relations in college students. Also, academic achievement was assessed by obtaining official documentation of students' GPAs from university records with participants' consent. Another unique aspect of the current study was the use of official probation and suspension data as measures of academic achievement. To our knowledge these variables have not been included as outcome variables in past research on parent relations in college students. The purpose of the current study was to assess the relationship between college students' perceptions of their relations with parents and their academic performance measured by official records of students' GPA and suspension/probation status. We hypothesized that perceived parent relations would be positively related to college GPA and negatively related to suspension/probation outcomes. We also were interested in determining whether the strength of these relationships differed for men and women. Finally, the generalizability of these findings was explored through replication at a similar university.

\section{Method}

\subsection{Participants}

Participants in Study I were 313 students (159 women and 154 men) enrolled in introductory psychology and sociology classes at a four-year liberal arts university in the southeastern United States. The students ranged in age from 18 to 29 years, with a mean age of 20.13 years $(S D=$ 1.55). The sample was comprised of $58.8 \%$ freshmen, $27.5 \%$ sophomores, $8.3 \%$ juniors, $5.1 \%$ seniors, and $0.3 \%$ non-degree seeking students. The ethnic break-down of the sample was as follows: $84.3 \%$ White, $10.5 \%$ Black, 1.6\% Asian, 1\% Hispanic, and 2.6\% Other.

The participants in Study II, the replication study, consisted of 153 students (122 women and 31 men) enrolled in undergraduate psychology courses at a nearby four-year liberal arts university. These students ranged in age from 18 to 27 years with a mean age of 21.83 years $(S D=1.65)$. The sample for the replication study consisted of $22.2 \%$ freshmen, $24.8 \%$ sophomores, $32.7 \%$ juniors, and $20.3 \%$ seniors. The ethnic break-down of this sample was as follows: $40.5 \%$ White, 56.2\% Black, 0.7\% Hispanic, and 2.6\% Other. 
Approval to conduct the studies was granted by the Institutional Review Board from each of the respective universities and the research was conducted in accordance with the ethical guidelines of the American Psychological Association [1]. All students in both studies volunteered to participate and provided written informed consent.

\subsection{Materials}

The Behavior Assessment System for Children $2^{\text {nd }}$ Edition Self Report of Personality College form (BASC-2 SRP-COL) [16] was used to measure participants' selfreported levels of perceived relations with parents. The BASC-2 SRP-COL is designed to measure various components of behavior, emotions, and self-perceptions of college-age young adults aged 18-25. The BASC-2 SRPCOL form consists of 185 items that require students to rate statements as either (T) True or (F) False on a fourpoint Likert scale using the following response options: (N) Never, (S), Sometimes, (O) Often, or (A) Almost Always. Individuals typically take about 20-30 minutes to complete the BASC-2 SRP-COL. The BASC-2 SRP-COL yields 16 subscales with scores reported as $T$ scores with a mean of 50 and a standard deviation of 10 . Twelve of the subscales are clinical scales designed to measure problematic types of behavior such as attention problems, alcohol abuse, anxiety, and depression. Four adaptive scales on the BASC-2 SRP-COL assess positive components of personality and behavior such as self-esteem, relations with parents, and interpersonal relations. $T$ scores of 70 and above on the clinical subscales are considered to be clinically significant while $T$ scores ranging from 60 to 69 are indicative of at-risk levels of characteristics that may lead to problems in functioning. For the adaptive scales, lower scores rather than higher scores represent problems in adaptive functioning. $T$ scores ranging from 31 through 40 are considered at-risk, and $T$ scores of 30 and below considered clinically significant.

Data from the Relations with Parents subscale of the BASC-2 SRP-COL were used in this study. Relations with Parents is one of the four adaptive subscales on the instrument and was designed to assess a young adult's self-reported perceptions about characteristics and quality of his or her relationship with parents. Questions concentrate on themes such as perceived level of parental involvement and trust, closeness to one's parents, and interaction time with parents. At-risk scores may indicate mild to moderate problems regarding relations with parents while clinically significant scores represent severe problems and possible estrangement from one's parents.

The BASC-2 SRP-COL has been shown to have good internal consistency with reliability coefficients of .90 for the Relations with Parents subscale for the combined gender norm and male and female samples [16]. The testretest reliability coefficient for the Relations with Parents subscale is .85 for college-age students. Evidence about the validity of the BASC-2 SRP-COL provided through factor analysis and correlations with other similar behavior measures is described in great detail in the manual.

\subsection{Procedure}

For Study I, the BASC-2 SRP-COL was administered to volunteers enrolled in introductory psychology and sociology courses during the first month of a sixteen-week semester. The university's Institutional Research and Assessment Department provided demographic and academic information which included participants' gender, age, ethnicity, class rank, cumulative GPA, and suspension and probation status. A similar procedure was used to provide a systematic replication for Study II at a nearby liberal arts university using BASC-2 SRP-COL data collected from volunteers enrolled in psychology courses. Demographic data and cumulative GPAs were obtained from official university records; however, suspension and probation outcome data were not available for the replication study.

\section{Results}

For both studies, $T$ scores on the Relations with Parents subscale of the BASC-2 SRP-COL were obtained using the BASC-ASSIST computer software program and students' cumulative GPAs at the end of the semester in which the BASC-2 SRP-COL was administered were obtained from official records at each university. Table 1 shows the means and standard deviations of the Relations with Parents $T$ scores and cumulative GPAs for participants in Study I and Study II.

Table 1. Means and Standard Deviations for Relations with Parents T Scores and Cumulative GPAs for Study I and I

\begin{tabular}{|c|c|c|c|c|c|c|}
\hline & \multicolumn{3}{|c|}{ Study I } & \multicolumn{3}{c|}{ Study II } \\
\hline $\begin{array}{c}\text { Relations with Parents } \\
\text { T Scores }\end{array}$ & $\mathrm{N}$ & $\mathrm{M}$ & $\mathrm{SD}$ & $\mathrm{N}$ & $\mathrm{M}$ & $\mathrm{SD}$ \\
\hline Entire Sample & 313 & 50.90 & 9.33 & 153 & 48.93 & 9.94 \\
\hline Men & 154 & 50.96 & 8.50 & 31 & 47.45 & 9.74 \\
\hline Women & 159 & 50.83 & 10.10 & 122 & 49.31 & 9.99 \\
\hline Cumulative GPAs & $\mathrm{N}$ & $\mathrm{M}$ & $\mathrm{SD}$ & $\mathrm{N}$ & $\mathrm{M}$ & $\mathrm{SD}$ \\
\hline Entire Sample & 313 & 2.96 & 0.70 & 153 & 2.70 & 0.59 \\
\hline Men & 154 & 2.84 & 0.69 & 31 & 2.61 & 0.63 \\
\hline Women & 159 & 3.07 & 0.69 & 122 & 2.72 & 0.58 \\
\hline
\end{tabular}

In Study I, the Relations with Parents scores ranged from 14 to 62 and the GPAs ranged from 0.80 to 4.00 . A significant positive correlation was found between Relations with Parents scores and GPAs for the entire sample of students in Study I, $r(311)=.149, p<.01$. The relationship between the two variables was then examined separately for female and male students. A significant positive correlation between Relations with Parents scores and GPAs was obtained for women, $r(157)=.223, p<.01$. For men, the two variables were positively correlated; however, the relationship was not statistically significant, $r(152)=.067, p,>.05$.

A second academic outcome variable, probation /suspension status, was recorded for participants in Study I. Using data collected by the university's Institutional Research and Assessment Department for a three year period following the administration of the BASC-2 SRPCOL each student was categorized as had been placed on academic probation or suspension or had not been placed on academic probation or suspension. Of the 313 participants in Study I, 28 students (12 women and 16 men) had been placed on academic probation or suspension and 285 students (147 women and 138 men) had not been placed on probation or suspension. A significant negative correlation was found between the Relations with Parents scores and probation/suspension 
status for the entire sample of students, $r_{p b}(312)=-.143, p$ $<.05$. When the relationship between Relations with Parents scores and probation/suspension status was examined separately for female and male students, a significant negative correlation was found between the variables for women, $r_{p b}(157)=-.258, p<.001$. A nonsignificant negative correlation between the variables was obtained for men, $r_{p b}(152)=-.026, p>.05$.

In Study II, the Relations with Parents scores ranged from 16 to 62 and the GPAs ranged from 1.00 to 3.90. A significant positive correlation was found between Relations with Parents scores and GPAs for the entire sample of students in Study II, $r(151)=.232, p<.01$. Separate gender analyses revealed a significant positive correlation between Relations with Parents scores and GPAs for female students, $r(120)=.234, p<.01$ and a nonsignificant positive correlation between the two variables for male students, $r(29)=.204, p>.05$. Analyses correlating probation/suspension status with Relations with Parents scores could not be conducted for Study II as official probation/suspension data were not available.

\section{Discussion}

As hypothesized, parent relations were positively related to college GPA and negatively related to probation/suspension outcomes. However, the magnitude of these relationships was relatively small when examining the entire sample of students for both Study I and Study II. These results are consistent with a recent meta-analysis examining psychological correlates of academic performance in college students which indicated that psychosocial and demographic variables tend to show small positive correlations with GPA [17]. Many variables impact the academic performance of college students, and the finding that a significant proportion of the variance, albeit small, in student performance can be attributed to relations with parents is noteworthy. Relations with Parents scores accounted for approximately 2\% of the variability in students' GPAs and $2 \%$ of the variability in probation/suspension status in Study I. When gender differences were evaluated in Study I, Relations with Parents scores accounted for more variance in GPA for women than men ( $5 \%$ versus $<1 \%$ ) and for more variance in probation/suspension status for women than men $(7 \%$ versus $<1 \%$ ). In Study II analyses of the relationship between parent relations and GPA for the entire sample and for women produced findings congruent with Study I. Relations with Parents scores accounted for $5 \%$ of the variability in students' GPA for the entire sample and accounted for $5 \%$ of the variance in academic performance for women. However, for men the relationship between the two variables was stronger in Study II than that found in Study I with parent relations explaining $4 \%$ of the variability in GPA.

Limitations of this research include that this was a correlational study, and therefore, it is not possible to determine that a causal link exists between parent support and academic performance. The selection process of the respondents for the study also could have affected the outcome since students chose to enroll in the courses in which the data were collected. It is possible that students with certain psychological and/or family backgrounds choose to enroll in psychology and sociology courses over other types of classes when options exist. However, given that similar degrees of relationship between a measure of parental support and academic performance were obtained in two separate university samples, it is possible that this result would generalize to college students at other institutions. College student personnel and counseling professionals who serve at-risk or academically struggling students may wish to assess students' perceived relations with and academic support from parents, in addition to the other variables when evaluating the reasons for students' academic difficulties.

The BASC-2 SRP-COL may be a particularly useful assessment instrument for use with college students. If questioned directly about relations with parents, students may be hesitant to report anything negative, but the BASC-2 SPR-COL objective question format may be less threatening. Also the BASC-2 SRP-COL measures other aspects of personality that could place students at-risk for academic problems and suspension/probation such as anxiety, depression, and alcohol abuse. With one instrument, multiple areas of functioning can be assessed all at once. Additionally, counseling personnel may be able to use the assessment data to help plan intervention strategies for students. For example, when students report positive relations with parents college student personnel may want to solicit parental assistance in developing a support plan. However, if parent relations are perceived as negative (at-risk on the BASC-2 SRP-COL) then other resources such as counselors, faculty or peer mentors may be more appropriate sources of support than parents.

In general, it may be important to better educate parents about the difference between supportive parental involvement that promotes autonomy and developmentally inappropriate over-involvement and psychological control. It should be noted that patterns of parent involvement and student/parent relations begin during the early elementary school years. School psychologists and other public school personnel may want to provide parent training and education about fostering positive relations with children and promoting positive ways of communicating with school personnel. Perhaps programs could be offered during students' senior year of high school for students and parents about transitioning to college. Program sessions could include students and parents discussing how the young adults plan to initiate support requests and maintain positive relations with parents and family while gaining independence and taking on more personal responsibility as they enter college. Colleges can assist with these efforts by holding parent orientation sessions, sponsoring student-parent events, and providing resources for parents such as websites, parent policy handbooks, and a clear listing of appropriate personnel to contact to resolve specific issues [3]. Open communication and a positive partnership between parents and university personnel may provide an integrated support system that facilitates college student success.

\section{List of Abbreviations}

BASC-2 SRP-COL: Behavior Assessment System for Children $2^{\text {nd }}$ Edition Self Report of Personality College Form 


\section{References}

[1] American Psychological Association, "Ethical principles of psychologists and code of conduct," American Psychologist, 57 1060-1073. Sep.2002.

[2] Carney-Hall, K.C., "Understanding current trends in family involvement," New Directions for Student Services, 122. 3-14. Jun.2008.

[3] Cutright, M. "From helicopter parent to valued partner: Shaping the parental relationships for student success,” New Directions for Higher Education, Winter (144). 39-48. Dec.2008.

[4] Day, R.D., \& Padilla-Walker, L.M., "Mother and father connectedness and involvement during early adolescence," Journal of Family Psychology, 23(6). 900-904. Dec.2009.

[5] Demaray, M., Malecki, C., Davidson, L.M., Hodgson, K.K., \& Rebus, P.J., "The relationship between social support and student adjustment: A longitudinal analysis,” Psychology in the Schools, 42(7). 691-706. Aug.2005.

[6] Duchesne, S., Ratelle, C.F., Larose, S., \& Guay, F., “Adjustment trajectories in college science programs: Perceptions of qualities of parents' and college teachers' relationship," Journal of Counseling Psychology, 54(1). 62-71. Jan.2007.

[7] Fan X., \& Chen, M., "Parental involvement and students' academic achievement: A meta analysis,” Educational Psychology Review, 13. 1-22. Mar.2001.

[8] Fass, M.E., \& Tubman, J.G., "The influence of parental and peer attachment on college students' academic achievement," Psychology in the Schools, 39(5). 561-573. Aug.2002.

[9] Fischer, J.L., Forthun, L.F., Pidcock, B.W., \& Dowd, D.A., "Parent relationships, emotional regulation, psychosocial maturity, and college student alcohol use problems," Journal of Youth and Adolescence, 36(7). 89-97. Oct.2007.

[10] Joussemet, M., Landry, R., \& Koestner, R., “A self-determination theory perspective on parenting,” Canadian Psychology, 49(3). 194-200. Aug.2008.

[11] Kolkhorst, B.B., Yazedjian, A., \& Toews, M.L., "Students' perceptions of parental support during the college years," College Student Affairs Journal, 29(1). 47-63. Fall.2010.
[12] Laible, D.J., Carlo, G., \& Roesch, S.C., "Pathways to self-esteem in late adolescence: The role of parent and peer attachment, empathy, and social behaviours,” Journal of Adolescence, 27(6). 703-716. Dec.2004.

[13] Lum, L., "Handling 'helicopter parents'," Diverse: Issues in Higher Education, 23(20). 40-42. Nov.2006.

[14] Pizzolato, J.E., \& Hicklen, S., "Parent involvement: Investigating the parent-child relationship in millennial college students," Journal of College Student Development, 52(6). 671-686. Nov/Dec.2011.

[15] Pomerantz, E.M., Moorman, E.A., \& Litwack, S.D., "The how, whom, and why of parents' involvement in children's academic lives: More is not always better," Review of Educational Research, 77(3). 373-410. Sep.2007.

[16] Reynold C. R., \& Kamphaus, R. W., Behavior Assessment System for Children (2nd ed.), American Guidance Services, Circle Pines, 2004.

[17] Richardson, M., Abraham, C., \& Bond, R., "Psychological correlates of university students' academic performance: A systematic review and meta-analysis," Psychological Bulletin, 138(2). 353-387. Mar.2012.

[18] Schiffrin, H.H., Liss, M, Miles-McLean, H., Geary, K.A., Erchull, M.J., \& Tashner, T., "Helping or hovering? The effects of helicopter parenting on college students' well-being,” Journal of Child and Family Studies, Feb.2013. [Online].

[19] Segrin, C., Woszidlo, A., Givertz, M., Bauer, A., \& Murphy, M.T., "The association between overparenting, parent-child communication, and entitlement and adaptive traits in adult children,” Family Relations, 61(2). 237-252. Apr.2012.

[20] Sorokou, C., \& Weissbrod, C., "Men and women's attachment and contact patterns with parents during the first year of college," Journal of Youth and Adolescence, 34(3). 221-228. Jun.2005.

[21] Wintre, M., \& Yaffe, M., “First-year students' adjustment to university life as a function of relationships with parents," Journal of Adolescent Research, 15(1). 9-37. Jan.2000.

[22] Yelle, D., Kenyon, B, \& Koerner, S.S., "College student psychological well-being during transition to college: Examining individuation from parents," College Student Journal, 43(4). 1145-1160. Dec.2009. 